\title{
Design of Rectangular Patch antenna with Parallel Slots for Medical Telemetry Applications
}

\author{
Navin M George, Anita Jones Mary Pushpa T
}

\begin{abstract}
In current scenario, rectangular patch antenna is used for applications such as Mobile telecommunications, Medical telemetry, Satellite communication, AM-FM broadcasting etc. Medical telemetry is a measurement at a distance from the subject; usually the measurable evidence of phenomena under investigation is transmitted by radio signals. The drawbacks of the existing methods are high cost of fabrication due to the usage of non-common substrates and the usage of frequencies which are not in wireless communication bands. A new design of rectangular patch antenna with parallel slot is proposed for overcoming this issue. The rectangular patch antenna having length $47.63 \mathrm{~mm}$ and width $37.9 \mathrm{~mm}$ and thickness 1.6mm with FR4 substrate and operating frequency is $2.4 \mathrm{GHz}$ for medical telemetry application in ISM band. The proposed antenna provides good return loss and achieves better gain. The simulation of rectangular microstrip patch antenna is analyzed using Ansoft/Ansys HFSS.
\end{abstract}

Index Terms- Microstrip antenna, Medical Telemetry, wireless body area network, ISM band.

\section{INTRODUCTION}

On the increase of compact antennas for medical telemetry applications the antenna size as well as the electronics size has been reduced rapidly. As the integration devices becomes smaller because of the impact of technology VLSI technology, the antenna sizes also needs to be brought down to the required scale down sizes. The usage of microstrip antennas which are comparatively low profile has been extensively used in this wireless application from communication to medical. The various structures such as rectangular, square, triangle, circular microstrips are commonly used for this purpose. Out of them rectangular is more widely used in major microstrip antennas at present irrespective of applications. The factors such as type of substrate material, physical dimension, feeding technique etc will determine the performance of the microstrip antenna. To enhance the gain vertical slots are being put on the microstrip of equal numbers with equal dimensions with equal spacing. The most common feeding technique which is the edge feeding is used to reduce the maximum loss in feeding. The substrate used is a very economic and easily available FR4 substrate, which brings down the material and the manufacturing cost.

Navin M George, Department of Electronics and Communication, Karunya Institute of Technology and Sciences, Coimbatore, Tamilnadu, India.(E-mail: mnavingeorge@gmail.com)

Anita Jones Mary Pushpa T, Department of Electronics and Communication, Karunya Institute of Technology and Sciences, Coimbatore, Tamilnadu, India.(E-mail: anitajones@karunya.edu)
Revised Manuscript Received on September 14, 2019.

\section{RELATED WORKS}

Tsolis A et. al [1] has presented review on wearable textile antennas using embroidery patch design on cloth fabric. This technique has advantages as follows: (i) large number of designs can be manufactured by using machinery. (ii) Doesn't require any gum for fixing. (iii) The designs are integrated to the fabric rather than fixing it. Al-Ashwal et. al [2] have designed two ultra-wideband (UWB) planar monopole antennas that the operating frequency ranging from $3.04 \mathrm{GHz}$ to $10.3 \mathrm{GHz}$ and from $3.04 \mathrm{GHz}$ to 11.3 GHz. These designs are tested under various operating conditions. Specific absorption rate of the design has also been analyzed. Liu et. al [3] Has discussed on a study of the properties of e-textile antennas for wearable applications. The simulation and measured result shows that the e-textiles undergone embroidery with distance between two conductive threads having $2 \mathrm{~mm}$ is considered to be metal plane to design antenna. M. S. Sakhirul et. al [4] has proposed integration of communication systems with textile antennas. The textile antenna provides a wide bandwidth for applications ranging from $3.1-10.6 \mathrm{GHz}$ at $10 \mathrm{~dB}$ return loss. The design have importance to minimum S11 $<210 \mathrm{~dB}$. Mai A.R Osman et. al [5] discuss the study of antenna under flexible conditions on textile substrate. The rectangular patch antenna consists of triangular slot operating in $2.4 \mathrm{GHz}$ for wearable applications and also having a bandwidth of $1.948-4 \mathrm{GHz}$. S. Sakarlingam et. al [6] has studied the radiation and impedance characteristics of $2.45 \mathrm{GHz}$ textile antenna. The circular microstrip antennas such as Flectron, Zelt antenna and Shieldit antenna. These antennas are analyzed with the presence of human torso with air gap $1 \mathrm{~mm}$. S. Zhu et. al [7] has analyzed the working of

dual-band coplanar patch antenna with electronic band gap is analyzed. The antenna substrate is

made from cloth and operates at 2.45 and $5 \mathrm{GHz}$ bands. The band gap consists of array three times three elements with reduced radiation over $10 \mathrm{~dB}$ and improved gain of 3 dB. P. M. Kannan et. al [8] has discussed on a dual band rectangular textile antenna operating at $0.9 \mathrm{GHz}$ and at 2.4 $\mathrm{GHz}$ is based on jeans substrate. The return loss obtained is only $-7 \mathrm{~dB}$. Afridi et. al [9] presents two types of dual band antennas of conventional and metamaterial types with operating frequency $(2.4$ and $5.8 \mathrm{GHz})$. One antenna is printed on a normal substrate and the other on a twodimensional metamaterial surface (EBG) structure. The 
APPLICATIONS

antenna has achieved a gain of $4.45 \mathrm{dBi}$. The EBG structure antenna has reduced the SAR effects on human body of levels $(<2 \mathrm{~W} / \mathrm{Kg})$. M. Mantash et. al [10] Has designed a "double G" flexible textile Co Planar Waveguide fed monopole antenna design for WLAN applications. The designed antenna can be used for Wi-Fi and 4G LTE applications working in $2.4 \mathrm{GHz}$ to $2.7 \mathrm{GHz}$ band and $5.1 \mathrm{GHz}$ to $5.875 \mathrm{GHz}$ band. The textile antenna is flexible, compact size, low cost and easy to integrate in garment. M. Svanda et. al [11] introduces a low-profile wearable RFID tag based on patches and vertically folded patches for Europe. The tag radiates at $866 \mathrm{MHz}$ and has a total area of $3 \mathrm{~mm}^{3}$ having an efficiency of $50 \%$. The antenna placed on the chest gave maximum read range of $7 \mathrm{~m}$, compared to other body parts. S. Singh et. al [12] presented a T shaped dual band microstrip patch antenna for wireless Lan communication in ISM band ranging from $2.4-2.5 \mathrm{GHz}, 5.7-$ $5.8 \mathrm{GHz}$ with coaxial feed. The antenna is having a length of $44 \mathrm{~mm}$ width of $36 \mathrm{~mm}$ height of $3 \mathrm{~mm}$.M. S. Shakirul et. al [13] presents an analysis of wearable antenna which is a Left-Handed Circular Polarization having different textile materials used as substrates for Global Positioning System application. The return loss, axial ratio, bandwidth and gain have been analyzed. The jeans substrate attained a optimum return loss of $-41.36 \mathrm{~dB}$ at $1.575 \mathrm{GHz}$ with that of other substrates. And also jeans have an improved bandwidth of $17 \mathrm{MHz}$ when compared to felt and cotton. S.Sngkarlingam et. al [14] has introduced a textile antenna with circular polarized square patch with different substrate materials. The analysis shows permittivity of the substrate has an impact on the antenna size and dimension. Jeans substrate provides a good return loss of -41.36 and a bandwidth of 17 $\mathrm{MHz}$ Felt substrate achieved a better gain of $3.2 \mathrm{dBi}$ when compared to jeans and cotton. While cotton will give more flexibility for antenna miniaturization. A. Sabban et. al [15] discuss a new technology using meta material and fractal technology for the manufacture of miniature sized antennas with better efficiency. The gain and directivity of an antenna with metamaterial can be increased by $2.5 \mathrm{~dB}$. Whereas using fractal antennas gives around $8 \mathrm{dBi}$ with 90 percentage efficiency. C. Kissi et al [16] present a study of on body antenna using lowest ultra wide bandwidth directive antennas. Experiments were conducted using male and female voxel with varying antenna to body distances. The parameters such as return loss, impedance, directivity, gain and efficiency. Bipa Dattal et. al [17] presents a design of pentagonal microstrip patch antenna of single band for improved gain and efficiency with operating frequency of $10.7591 \mathrm{GHz}$ and $11.1806 \mathrm{GHz}$. The antenna has single layer substrate and one side fully ground plane. The size has been reduced to $52.64 \%$ with increased frequency ratio. A. Y. I. Ashyap et. al [18] designed a miniaturized textile antenna for ISM band applications operating at $2.4 \mathrm{GHz}$. It uses rectangular slot with strip line to form inverted Eshaped antenna. The structure uses fabric substrate hence size is reduced $75 \%$ than conventional antenna. The impedance, efficiency and bandwidth have also shown desirable increase. M. Y. El Salamouny et. al [19] proposes two new designs for low profile multi band microstrip antennas. First is using ISM bands ranging from $(2.4 \mathrm{GHz}$ to $5.8 \mathrm{GHz}$ ) commonly used in wireless body area networks.
Second one is using stacking design that operates in $3.5 \mathrm{GHz}$ and $7.5 \mathrm{GHz}$, which is mostly used for Ultra-Wide-Band (UWB) applications. Both antennas are compact in size as well as they are having minimum SAR values in compliance with safety standards. K. N. Bocan et. al [20] designed and evaluated printed antenna topologies for ultra high frequency and to have a study on the effect of human body tissues. Loop antenna gives more gain with smallest of size in implantable antenna. Dipole gives higher gain with scope of improvement on extension. The antennas performance was studied on placing at various body levels. Sabban et. al [21] Designed small antennas with high efficiency using metamaterial and fractal technology. Different types of printed metamaterials and fractal antennas are discussed. The gain and directivity is increased by $2.5 \mathrm{~dB}$ in metamaterials based antenna. A. Kiourti et. al [22] presented a new class of wearable antennas based on embroidery using metal coated polymer threads also called as e-threads. The prototypes are flexible, robust, and lightweight. This technology brings improvement in manufacturing of RF communication in medical, military and other applications. R. M. Shubair et. al [23] presents two designs using miniature microstrip antenna for wearable biotelemetry applications in Industrial, Scientific, and Medical (ISM) band (2.4-2.48GHz). The proposed designs have stacked triangular guiding patches and with slotted ones. The size reduction of $60 \%$ is achieved as well as return loss of -16.69 for stacked and $-15.53 \mathrm{~dB}$ for slotted. Furthermore the SAR analysis shows the values in the permissible safety ranges. V. T. Nguyen et.al [24] has designed a radiation pattern reconfigurable antenna for radio communications in medical devices in (Med Radio band: 401-406 MHz). Two artificial switches are provided to perform reconfigurable property. The size of the antenna is only $193.3 \mathrm{~mm}^{3}$ and uses a commonly available substrate FR4.Green et. al [25] designed an antenna operating in $2.4 \mathrm{GHz}$ ISM band. Indium Tin Oxide (ITO) is used in this antenna as substrate which is transparent in nature. The return loss of the designed antenna is approximately $-13 \mathrm{~dB}$.

\section{ANTENNA DESIGN}

\section{A. Design Procedure}

The proposed antenna is designed to work in the wireless frequency range for medical applications which is $2.4 \mathrm{GHz}$. The design is based on a rectangular patch antenna with two identical parallel slots with impedance matching done at 50 ohms. In order to tune the appropriate frequency two identical slots are made in both the sides of the patch. The feeding of the antenna is given to a long thin radiating strip which is connected to the BNC connector at the tip of the antenna. All the dimensions are annotated in the figure 6.1 with units in (mm). The whole antenna is designed in a FR4 substrate with $1.6 \mathrm{~mm}$ thickness. 


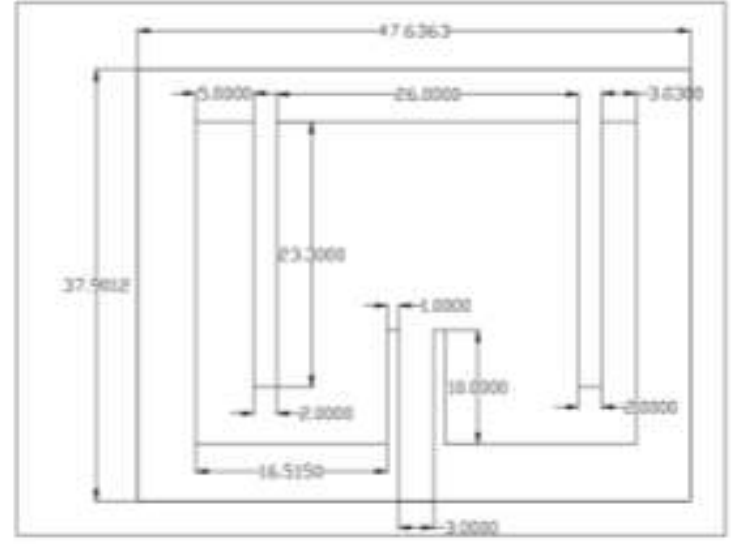

Fig. 1 Dimensions of the proposed dual slot antenna.

The proposed model is designed as per the antenna design equations and the dimensions for the same are mentioned in the figure 1. The design is simulated in Ansys HFSS with a range of frequencies ranging from $0-3 \mathrm{GHz}$. Where which the antenna was found radiating at $2.4 \mathrm{GHz}$ which is the frequency for wireless medical telemetry application. The Simulated design is fabricated using eleven labs, a prototyping machine. The fabricated prototype is tested using keysight network analyzer for the standardization of the simulated results.

\section{B. Design Equations}

The microstrip patch antenna dimensions can be derived from the following equations. Firstly the width of the patch and its effective dielectric constant $\left(\varepsilon_{\text {reff }}\right)$ can be found out as follows.

$$
\begin{gathered}
W=\frac{c}{2 f_{0}} \sqrt{\frac{2}{\varepsilon_{r}+1}} \\
\varepsilon_{\text {reff }}=\frac{\varepsilon_{r+1}}{2}+\frac{\varepsilon_{r-1}}{2}\left[1+12 \frac{h}{W}\right]^{-\frac{1}{2}}
\end{gathered}
$$

The length $(\mathrm{L})$ of the patch can be determined by the equation as follows where $\Delta L$ the length difference of the patch.

$$
\begin{gathered}
\frac{\Delta L}{h}=0.412 \frac{\left(\varepsilon_{\text {reff }}+0.3\right)\left(\frac{w}{h}+0.264\right)}{\left(\varepsilon_{\text {reff }}-0.258\right)\left(\frac{w}{h}+0.8\right)} \\
\mathrm{L}=\frac{\mathrm{C}}{2 \mathrm{f}_{0 \sqrt{\varepsilon_{\text {reff }}}}}-2 \Delta L
\end{gathered}
$$

Length of the ground plane $(L g)$ is derived from the above equation.

$$
L g=6 h+L
$$

Width of the ground plane $(W g)$ is derived from the above equation.

$$
W g=6 h+W
$$

Wavelength of the transmission line $\left(\lambda_{\mathrm{d}}\right)$ is derived from length of transmission line $\left(L_{S}\right)$

$$
\begin{aligned}
& \lambda_{\mathrm{d}}=\frac{\lambda}{\sqrt{\varepsilon_{r}}} \\
& L_{s}=\frac{1}{4} \lambda_{\mathrm{d}}
\end{aligned}
$$

Insertion distance $Y_{0}$ and insertion gap $I_{g}$ are derived as:

$$
Y_{0}=\frac{L}{2}-\left(\frac{L_{s}}{2}+L_{p}\right)
$$

$$
I_{g}=\frac{C}{\sqrt{2 \varepsilon_{\text {reff }}}} \frac{4.65 \times 10^{-12}}{f_{0}}
$$

Where:

$$
\begin{gathered}
L_{p}=\text { Port Width } \\
f_{0}=\text { Operating Freequency }
\end{gathered}
$$

\section{SIMULATION PROCEDURE}

\section{A. Creating substrate}

The substrate material we are using is denim. Now a substrate is created with the dimension length of length $=47.63 \mathrm{~mm}$, width $=37.9 \mathrm{mmand}$ thickness $=1.6 \mathrm{~mm}$. The substrate is of FR4 with $\Sigma \mathrm{r}=4.4$.

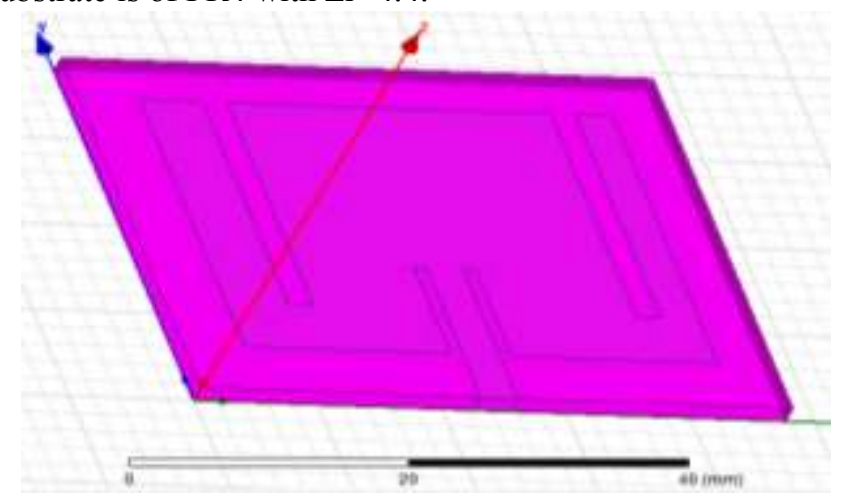

Fig. 2 substrate of the antenna is created with FR4 material.

\section{B. Creating Ground Plane}

Rectangular ground plane is created with length, breadth and dimensions as length $=47.63 \mathrm{~mm}$, width $=37.9 \mathrm{~mm}$. This full ground plane gives a maximum reflection of radiation towards the perpendicular radiating direction, with less loss as reflection in the opposite direction.

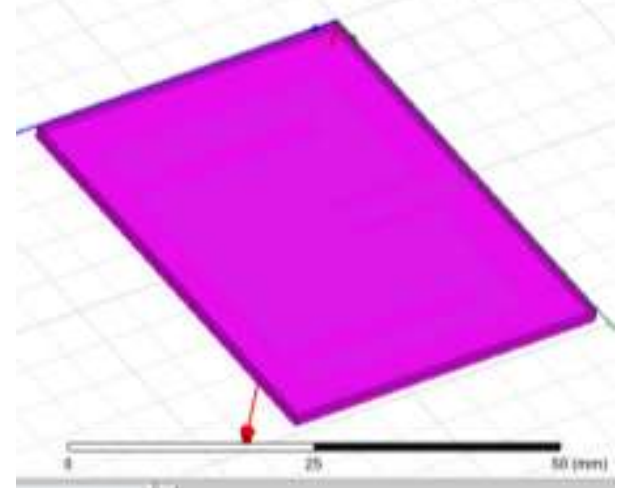

Fig. 3Ground Plane of the antenna is created with fully conductive surface.

\section{Creating a Rectangular Patch}

Rectangular patch with length $=47.63 \mathrm{~mm}$, width $=37.90$ $\mathrm{mm}$ on the substrate. The patch created will be assigned perfect electric conductor. 


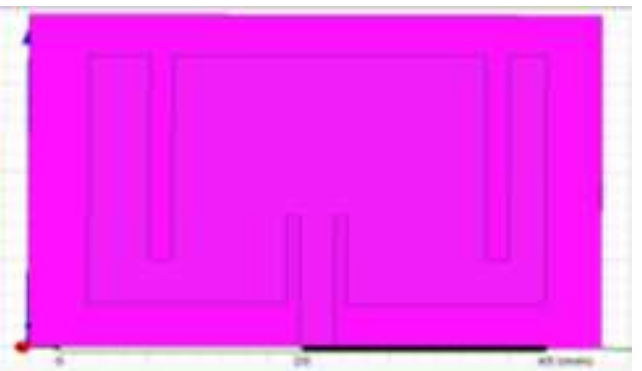

Fig. 4 Rectangular Patch is created on top of the antenna.

\section{Creating a Slot}

Rectangular slots are created on both sides on the micro strip antenna with dimensions length $=23$ and width $=2 \mathrm{~mm}$ and another slot with length $=10$ and width $=1 \mathrm{~mm}$

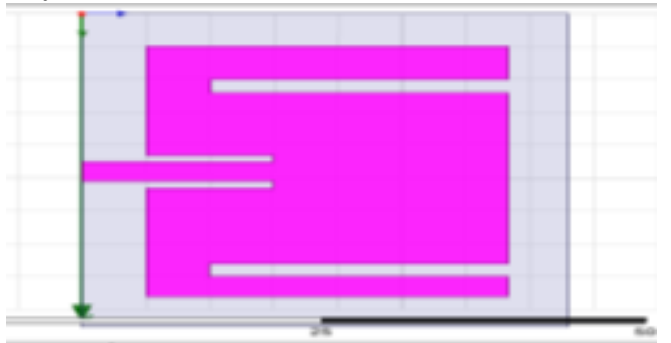

Fig. 5 Rectangular slots are created on both sides of the patch.

\section{E. Creating Port}

Create a port and change its property to perfect electric conductor material. The extended conductor towards the thickness of the substrate is made to give the excitation.

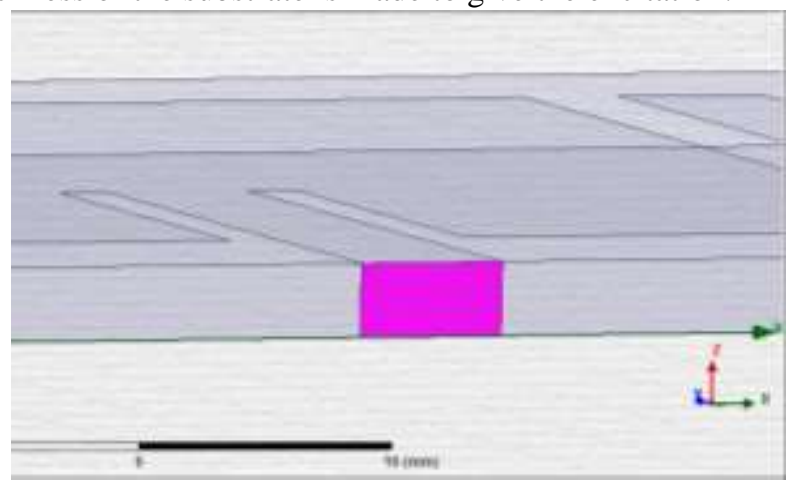

Fig. 6 Creating a metallic element to assign port.

\section{F. Creating Feed}

Feed points are created with the help of start point and end point and with property of perfect $E$ dielectric material on the strip extension from the feed line towards the side of the substrate. Floquet port is used in

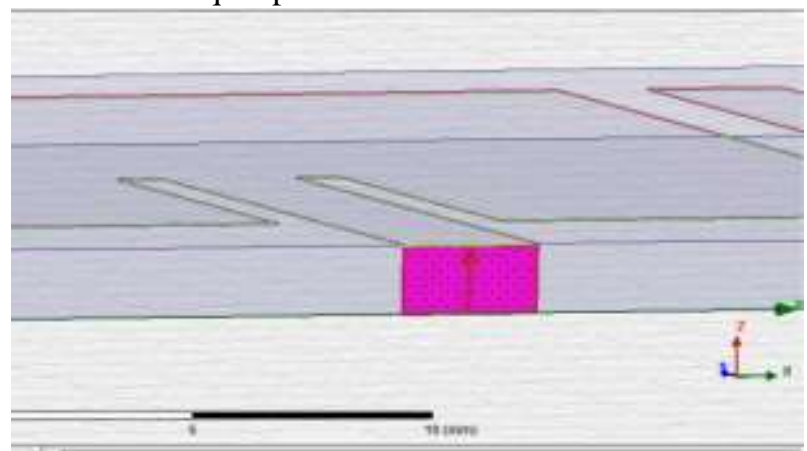

Fig.7 Floquet Port is assigned for the metallic element. respectively.

\section{SIMULATION RESULTS}

The proposed antenna is simulated in Ansys HFSS and the results for radiation pattern, return loss, VSWR, gain and directivity are observed. The proposed antenna is also tested for the return loss, VSWR and impedance. The obtained results from simulation and testing are compared for the analysis.

\section{A. Radiation pattern at $2.4 \mathrm{GHz}$ (Simulated)}

Radiation pattern defines how the power is distributed by the antenna towards various directions away from the antenna. This power distribution is analyzed on the basis of far field radiation. The maximum radiation is usually denoted by red color and lowest radiation is denoted by blue and in between ranges will be denoted by yellow and green. The ideal antenna will have the maximum radiation pattern oriented perpendicular to the base plate. The radiation which is falling on the opposite direction is called as reflection or loss.

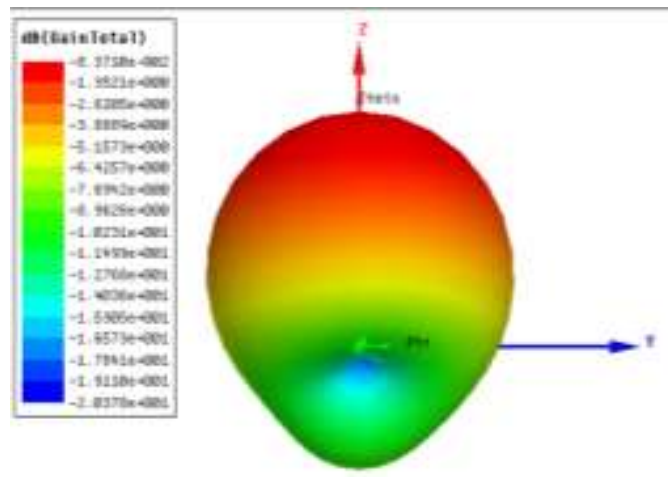

Fig. 8 3D radiation pattern of proposed antenna.

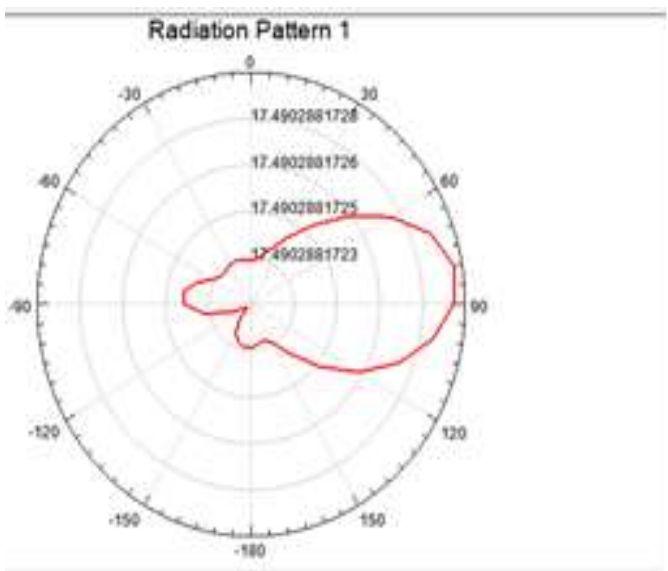

Fig.9 Radiation Pattern at of the proposed $2.4 \mathrm{GHz}$

\section{B. Return Loss (Simulated)}

Return loss of an antenna is the ratio of the signal which is going out as loss from the input of the antenna after acceptance. The ratio is specified in decibels $(\mathrm{dB})$ other than in short circuit where $100 \%$ rejection is occurred. In this model the return Loss or $\left(\mathrm{S}_{11}\right)$ is -13.31 which shows that this this antenna radiates maximum power in $2.4 \mathrm{GHz}$.

Published By: 


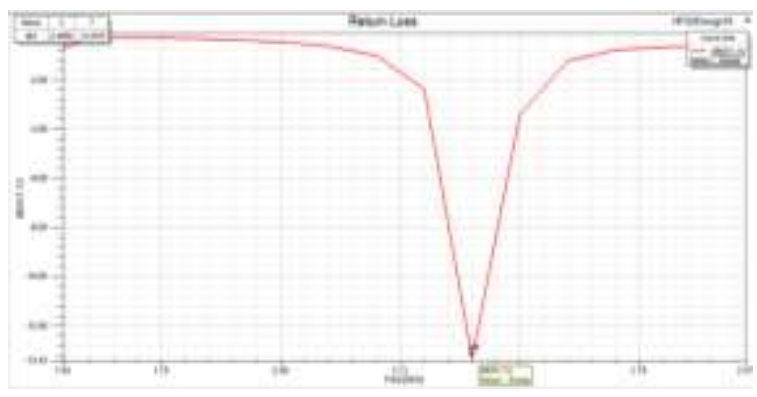

Fig. 10 Return loss of the antenna at $2.4 \mathrm{GHz}$.

\section{VSWR (Simulated)}

Voltage standing wave ratio defines numerically how well the antenna impedance is matched with the antenna to which it is connected. Standing waves are formed when there is mismatch in the impedance of the input circuitry and the antenna feed. The standard impedance is taken as 50 ohms. If there happens to be any impedance miss match the antenna will not be able to give the maximum performance as it is supposed to give. This will also result in power loss and reflected energy. It is one of the procedures to measure for any imperfections in the transmission lines.

The obtained VSWR is 4 which shows that the antenna has less power are only reflected from the antenna.

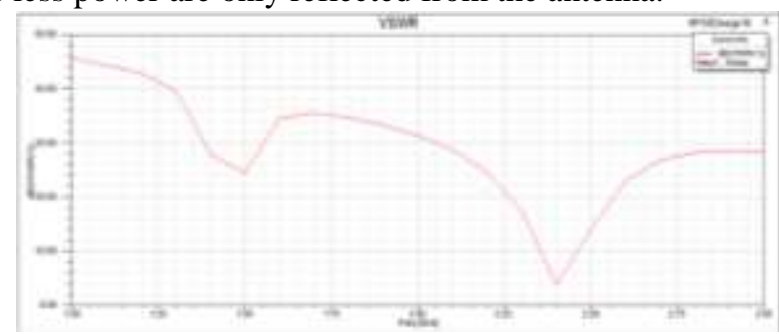

Fig. 11 VSWR of the antenna at $2.4 \mathrm{Ghz}$.

\section{Gain (Simulated)}

The gain of an antenna is defined as the maximum power at which the antenna radiates in a particular direction. Gain is more considered than directivity of an antenna because gain will not take into account of all the losses that happens in an antenna. Antenna gain will be normally analyzed on the basis of far field radiation analysis by a hypothetical lossless isotropic antenna.

The proposed antenna gives a maximum gain of $30 \mathrm{dbm}$ practically for $2.4 \mathrm{GHz}$.

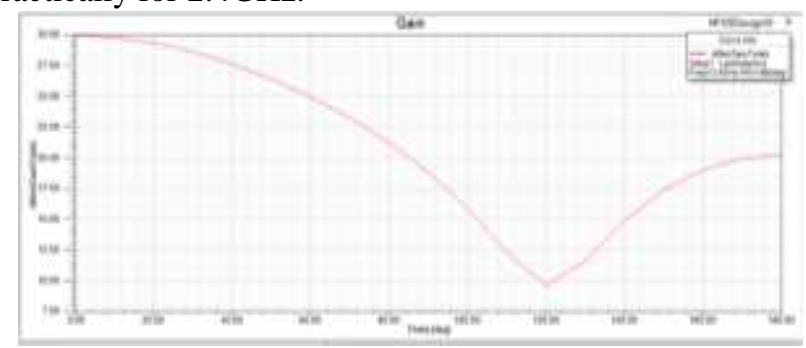

Fig. 12 Gain of the antenna at $2.4 \mathrm{Ghz}$.

\section{E. Directivity (Simulated)}

It is an antenna parameter which measures the degree at which the radiation emitted is concentrated in a same direction. It measures the power density of the antenna radiating in a particular direction with respect to an ideal isotropic antenna. Directivity is another component of antennas gain which is analyzed on a directional perspective. The proposed antenna is giving a maximum directivity of 1.76 at $2.4 \mathrm{Ghz}$.

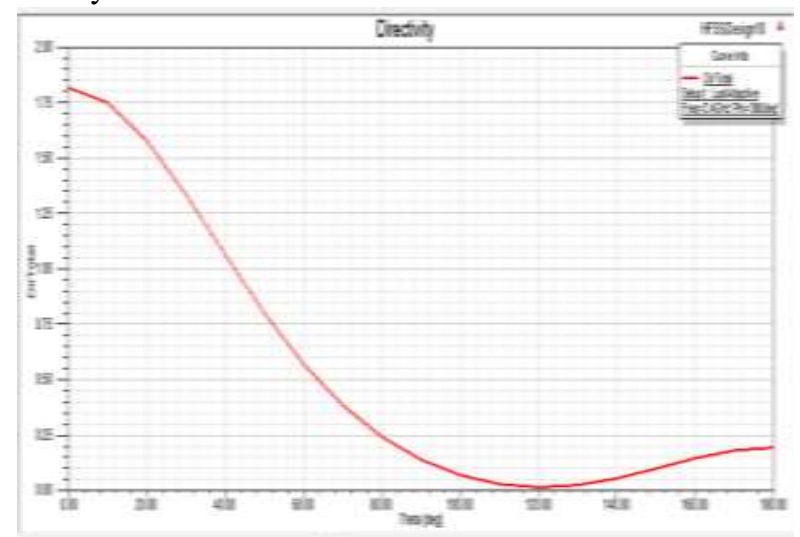

Fig. 13 Directivity of the antenna at $2.4 \mathrm{Ghz}$.

\section{F. Impedance (Simulated)}

Impedance of an antenna is the resistance of the whole antenna system at its feeding point. The impedance of the antenna will be changed with respect to frequency of the same. An antenna with positive impedance will be considered to be radiating. The impedance of the antenna needs to be matched with the impedance of the circuit to be connected to make sure that the antenna functions with maximum response.

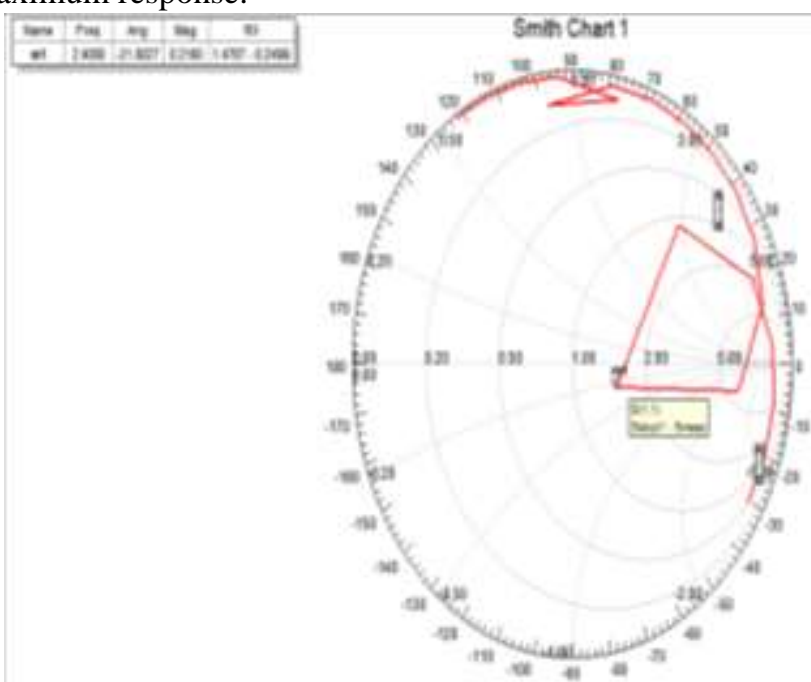

Fig. 14 Impedance of the antenna at $2.4 \mathrm{Ghz}$.

\section{ANTENNA FABRICATION.}

The dual slot microstrip patch antenna is fabricated using Eleven Lab prototyping machine. The antenna is fabricated with dual layer copper plated FR4 substrate with $1.6 \mathrm{~mm}$ thickness. The design from HFSS is scaled to a two dimensional design and exported to cad format. The cad format file is imported in eleven labs and the fabrication is dome. 


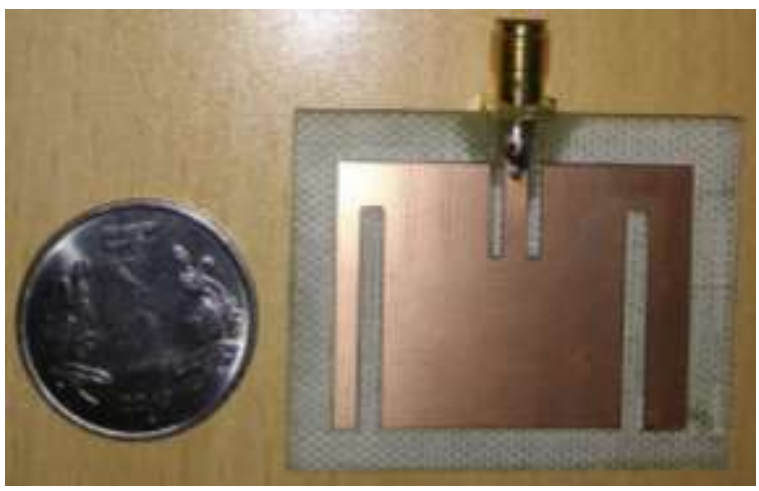

Fig. 15 Top view of the fabricated antenna.

After the fabrication is done the unwanted parts are filed and made smooth. An SMA connector is connected to the feed line and soldered for continuity. The top view and the bottom view are shown in the figure 15 and 16. The ground of the SMA connector is soldered to the ground plane and feed line to the signal probe.

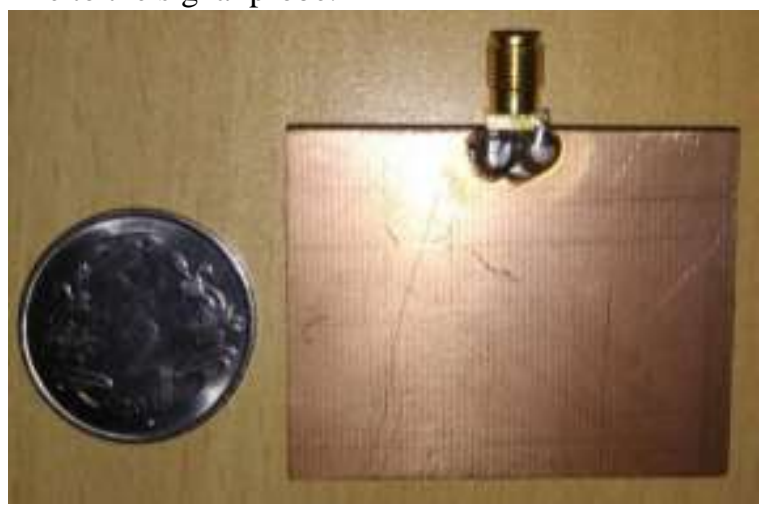

Fig. 16 Bottom view of the fabricated antenna.

\section{TESTING RESULTS}

The testing is carried out by keysight field fox vector network analyzer. The parameters such as return loss, VSWR and gain have been analyzed for the fabricated antenna.

\section{A. Return Loss (Tested)}

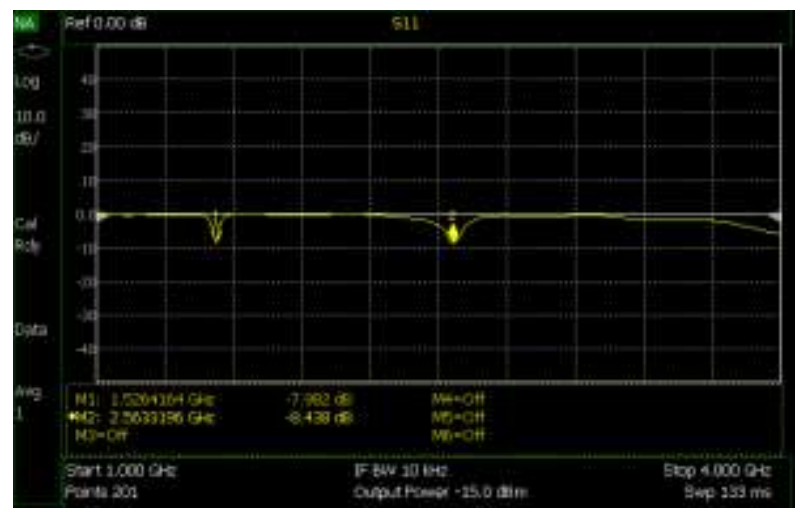

Fig. 17 Return Loss of the antenna while testing.

The return loss obtained from the antenna at $2.56 \mathrm{GHz}$ is $8.438 \mathrm{db}$. This is very much less compared to the simulated results. The reduction is mainly because of the imperfections in the antenna design. Since milling method is used the substrate thickness has been reduced.
B. VSWR (Tested)

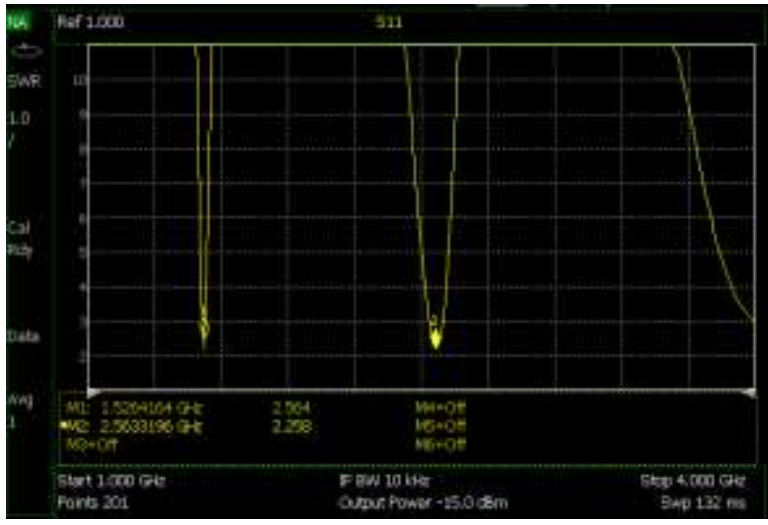

Fig. 16 VSWR of the antenna while testing.

The voltage standing wave ratio for an ideal antenna should be approximately equal to 2 . In the test result the VSWR value of the dual band microstrip antenna at $2.4 \mathrm{GHz}$ is equal to 2.25 . So we can conclude that the standing waves generated at the feeder is less.

\section{Impedance (Tested)}

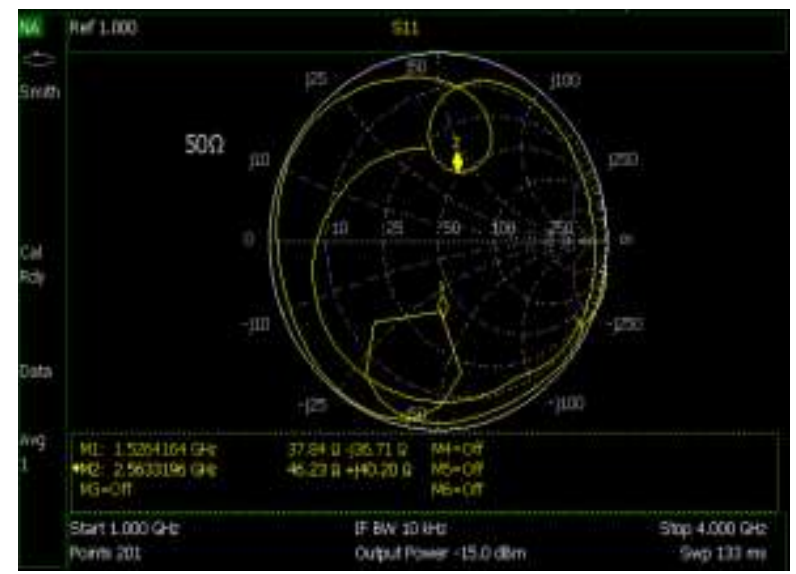

Fig. 16 Impedance of the antenna while testing.

The impedance matching is very much required for the antennas to get interfaced with any system. The standard impedance matching range will be $50 \mathrm{ohms}$ where which the antenna and the corresponding circuitry has to attain the same impedance to give good performance. Here in our tested prototype the antenna has attained $46.23 \mathrm{ohms}$ at 2.56 Ghz. Hence the impedance matching has to be done in the circuit side to match up with the impedance of $50 \mathrm{ohm}$.

\section{CONCLUSION}

From this paper it can be concluded that dual slot rectangular patch antenna can operate at resonance frequency of $2.4 \mathrm{GHz}$ which is useful for wireless telemetry application. The resonance frequency is highly dependent on the dual slots in the rectangular patch antenna. The slot loaded patch antenna exhibits full ground in order to have maximum gain. All the parameters are simulated and theoretically calculated, current distributions are observed. Thus we conclude our antenna to be efficient after varying and comparing the slot length, slot width and substrate thickness at various values.

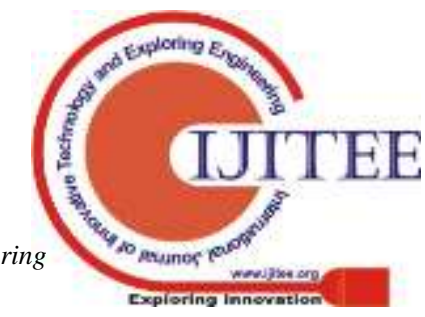




\section{REFERENCES}

1. Tsolis A, G.Whittow W, A.Alexandridis A and Vardaxoglou J.C. 2014. Embroidery and Related Manufacturing Techniques for Wearabe Antenna Challenges and Opportunities, Electronic, 3, 314-338.

2. Al-Ashwal, W. A. M., Ramli, N. K., Mohamud Shire, A. 2014.,"Performance of ultra-wideband wearable antenna under severe environmental conditions and specific absorption rate (SAR) study at near distances", ARPN Journal of Engineering and Applied Sciences, Vol 10(4), 1613-1622.

3. Liu, N, Lu, Y., Qin, S. " Electromagnetic properties of the Electron Textile forWearable Antenna", Applic.FrontElectr.Electron.Eng,,6,.553-55

4. M. S. Sakhirul, M. Jusoh, A. Sahadah, C. M. Nor and Hasliza A. Rahim,2014Embroided wearable textile antenna on bending and wet performances forreception", Microwave and Optical Technology Letters, Vol.56, 2158-2163.

5. Mai A.R Osman, M. K. A. Rahim, N. A. Samsuri, M.E. Ali, "UWB Wearable Teknologi, 58, pp.39-44, 2012.

6. S. Sakarlingam, S. Dhar, B. Gupta, L. Osman, K. Zeouga and A. Gharsallah,2013."Performance of Electro tectile wearable circular patch antennas in thevicinity of human body at $2.45 \mathrm{GHz}$ ", Procedia Engineering Elsevier, 64, 179-184.

7. M. Mantash, S. Collardey, A. C. Tarot and A. Presse, 2013." Dual band WiFi And 4G LTE Textile Antenna", 7th European Conference on Antenna and Propagation (EUCAP), 422-425.

8. M. Svanda and M. Polivka, 2014. " Small size wearable high efficiency TAG antenna for UHF RFID of people", International Journal of Antennas and propagation, vol.2014,.15.

9. S. Singh, R. K. Gangwar, and S. Agarwal, 2014." A dual band T- shaped Microstrip antenna for Wearable Applications", International Journal of Electronicand Electrical Engineering, Vol.7, no.2,195-200.

10. M. S. Shakirul, M. Jusoh, A.H. Ismail, M. R. Kamrudin, R. Yahya, M.N.M . yasin and T. Sabapathy 2014., " 1.575 GHz Circular Polarization Wearable Antenna with Three Differents Substrate Materials", IEEE Asia Pacific Conferenceon Applied Electromagnetic (APACE). 4346.

11. S.Sngkarlingam and B.Gupta, 2012 "Effects of Bending on Impedance andRadiation Characteristics of Rectangular Wearable Antenna Utilizing SmartClothes", Microwave and Optical Technology Letters, vol.54, no.6,1508-1511.

12. A. Sabban, "Small wearable antennas for wireless communication and medical systems," 2018 IEEE Radio and Wireless Symposium (RWS), Anaheim, CA, 2018, pp.

161-164. doi: 10.1109/RWS.2018.8304974

13. C. Kissi et al., "Low-UWB Antennas in Vicinity to Human Body," 2019 13th International Symposium on Medical Information and Communication Technology (ISMICT), Oslo, Norway, 2019,pp.1-6.doi: 10.1109/ISMICT.2019.8744000

14. Bipa Datta1,a, Moumita Mukherjee2,b, "Design of A Single Band Pentagonal Microstrip Patch Antenna for purpose of Medical Equipment" Journal of Physics Through Computation (2019) Vol. 2: 30-36, DOI: 10.23977/jptc.2019.21007ISSN 2617-1163

15. A. Y. I. Ashyap et al., "Inverted E-Shaped Wearable Textile Antenna for Medical Applications," in IEEE Access, vol. 6, pp. 35214-35222, 2018. doi: 10.1109/ACCESS.2018.2847280

16. M. Y. ElSalamouny and R. M. Shubair, "Novel design of compact low-profile multi-band microstrip antennas for medical applications," 2015 Loughborough Antennas \& Propagation Conference (LAPC), Loughborough, 2015, pp. $1-4$ doi: 10.1109/LAPC.2015.7366015

17. K. N. Bocan, M. H. Mickle and E. Sejdić, "Tissue Variability and Antennas for Power Transfer to Wireless Implantable Medical Devices," in IEEE Journal of Translational Engineering in Health and Medicine, vol. 5, pp. 1-11, 2017, Art no. 2700111 doi: 10.1109/JTEHM.2017.2723391

18. Sabban, Albert ${ }^{1}$, "Small Wearable Meta Materials Antennas for Medical Systems" Applied Computational Electromagnetics Society Journal. Apr2016, Vol. 31 Issue 4, p434-443. 10p.

19. A. Kiourti and J. L. Volakis, "Wearable antennas using electronic textiles for RF communications and medical monitoring," 2016 10th European Conference on Antennas and Propagation (EuCAP), Davos, 2016, pp. 12. doi: 10.1109/EuCAP.2016.7481222

20. R. M. Shubair, A. M. AlShamsi, K. Khalaf and A Kiourti, "Novel miniature wearable microstrip antennas for ISM-band biomedical telemetry," 2015 Loughborough Antennas \& Propagation Conference (LAPC), Loughborough, 2015, pp. 1-4 doi: 10.1109/LAPC.2015.7366008

21. V. T. Nguyen and C. W. Jung, "Radiation-Pattern Reconfigurable Antenna for Medical Implants in MedRadio Band," in IEEE Antennas and Wireless Propagation Letters, vol. 15, pp. 106-109, 2016 doi: 10.1109/LAWP.2015.2432172

22. Green, R. B., Toporkov, M. , Ullah, M. , Avrutin, V. Ozgur, U. , Morkoc, H. and Topsakal, E. (2017), An alternative material for transparent antennas for commercial and medical applications. Microw. Opt. Technol. Lett., 59: 773-777.doi:10.1002/mop.30404 